\section{A invenção da norma: a psicologia na Liga Brasileira de Higiene Mental}

\section{Inventing the standard: psychology in the Brazilian Mental Hygiene League}

\section{Fernando A. Figueira do Nascimento ${ }^{i}$}

Doutorando, Instituto de Psicologia/Universidade de São Paulo. São Paulo - SP - Brasil orcid.org/0000-0001-7223-3047 fernandofigueira76@hotmail.com

\section{Belinda Piltcher Haber Mandelbaum ${ }^{i i}$}

ii Professora, Departamento de Psicologia Social e do Trabalho, Instituto de Psicologia/Universidade de São Paulo. São Paulo - SP - Brasil

orcid.org/0000-0002-5285-1427

belmande@usp.br

Recebido em 23 set. 2018

Aprovado em 8 jan. 2019.
NASCIMENTO, Fernando A. Figueira do; MANDELBAUM, Belinda Piltcher Haber. A invenção da norma: a psicologia na Liga Brasileira de Higiene Mental. História, Ciências, Saúde - Manguinhos, Rio de Janeiro, v.27, n.4, out.-dez. 2020, p.1149-1167.

Resumo

$\mathrm{O}$ artigo analisa a psicologia na Liga Brasileira de Higiene Mental, instituição fundada em 1923 que tinha como princípios fundamentais a adaptação dos indivíduos e a constituição da "moral universal do amanhã". Entre outras proposições, ela se dedicou à adaptação de testes psicológicos e aos estudos sobre o desenvolvimento infantil que buscavam avaliar o funcionamento mental e delimitar sua norma. Como elemento que colaborou para a extensão do poder psiquiátrico, a psicologia implicou-se em duas dimensões da atuação do poder disciplinar: os corpos individuais e o corpo social. Assim, a psicologia também encontrou a possibilidade de sua vulgarização, não sem as contradições emergentes na posição de saber e técnica disciplinar.

Palavras-chave: história das ciências; história da psicologia; higienismo; biopolítica; psicologia.

Abstract

The article analyzes psychology within the Brazilian Mental Hygiene League, an institution founded in 1923 for the adaptation of individuals and to shape the "universal morals of tomorrow." Among other purposes, the league worked to adapt psychological tests and studies on child development in an attempt to assess mental function and establish standards. As an element that helped broaden the power of psychiatry, psychology was involved in two dimensions of disciplinary power: individual bodies and the social body. In this way, psychology also encountered the possibility that it could be vulgarized, as well as contradictions arising from the position of knowledge and techniques in this area.

Keywords: history of science; history of psychology; hygienism; biopolitics; psychology. 
$\mathrm{O}$ objetivo deste artigo é compreender a recepção e a constituição dos saberes psicológicos no interior da Liga Brasileira de Higiene Mental (LBHM), tendo como base os artigos originais publicados nos Arquivos Brasileiros de Higiene Mental, periódico mantido pela LBHM entre 1925 e 1947. Selecionamos os trabalhos dos Arquivos que consideravam a psicologia, o que incluía a psicologia experimental, a psicometria e a psicologia aplicada, saber propedêutico para a psiquiatria.

A constituição dos saberes psicológicos no Brasil esteve relacionada aos processos de transformação social que resultaram no desenvolvimento de dispositivos para o gerenciamento ou o controle da saúde, da educação, da religião, da moral e de várias outras dimensões da experiência dos indivíduos. Nesse sentido, a psicologia esteve implicada em fornecer subsídios teóricos, propedêuticos, para os campos do direito, da pedagogia e da medicina desde o século XIX (Massimi, 1990).

No campo do direito, a psicologia foi considerada a ciência mais abrangente sobre o homem, aquela que poderia permitir ao legislador maior discernimento a respeito das ações humanas, das modificações do comportamento, das diferenças individuais, assim como de todo um conjunto de funções presentes na origem das ideias, das sensações e das paixões individuais e sociais (Massimi, 1990).

A pedagogia interessou-se pelo estudo da relação entre os saberes psicológicos e os métodos de ensino que proporcionariam ao educador maior conhecimento sobre seus educandos. Nessa perspectiva, tornava-se fundamental a compreensão do desenvolvimento infantil e dos processos relacionados à aprendizagem, à inteligência, às sensações e à vontade (Antunes, 2007).

Por sua vez, foi no campo da medicina que surgiram muitos dos trabalhos sobre os assuntos psicológicos.

Permeada pela mentalidade positivista e, ao mesmo tempo, baseando-se na preexistência de tradição de interesse pelos assuntos psicológicos - documentada pelas teses apresentadas nas faculdades ao longo do século XIX - a medicina representa, no fim do século XIX e início do século XX, uma área particularmente propícia à constituição da Psicologia Científica no Brasil (Massimi, 1990, p.65).

De maneira geral, essas teses tratavam de temas como criminalidade, psicofisiologia, hipocondria, sexualidade, educação física e moral, higiene mental e escolar, emoções, doença mental, histeria e outros de caráter psicossocial que poderiam ser considerados pertencentes à psiquiatria e à medicina social (Antunes, 2007; Soares, 2010).

Entre as instituições médicas que se interessaram pela psicologia e contribuíram para sua produção de saber no país está a LBHM, fundada por Gustavo Riedel ${ }^{1}$ em 1923, tendo em seus quadros psiquiatras, políticos e intelectuais, além de representantes da indústria, do comércio e do funcionalismo público. Vale mencionar que entre seus integrantes honorários estava o então presidente da República, Arthur Bernardes. Juliano Moreira ${ }^{2}$ e Henrique Roxo $^{3}$ foram presidentes de honra da instituição (LBHM, 1925; Lourenço Filho, 2004).

A Liga estimulou a produção de estudos sobre os processos mentais e reconheceu a psicologia não como uma ciência afim à psiquiatria, mas um saber propedêutico e fundamental para o desenvolvimento de ações no campo da higiene mental. A LBHM 
fundou, em 1926, um laboratório de psicologia cuja direção foi confiada ao francês Alfred Fessard $^{4}$ e, posteriormente, a Plínio Olinto, ${ }^{5}$ que foi sucedido por Brasília Lemes Lopes, ${ }^{6}$ tendo esta última contribuído para a adaptação dos testes psicológicos (Antunes, 2007). Além de apoiar as tentativas de adaptação dos testes, a LBHM também realizou as Jornadas Brasileiras de Psicologia e o Seminário Brasileiro de Psicologia, com reuniões semanais de estudo (Lourenço Filho, 2004).

Aos saberes psicológicos caberia não apenas auxiliar na adaptação dos sujeitos, tarefa fundamental para a higiene mental, e na assistência aos doentes mentais, mas sobretudo ser capaz de determinar os limites entre o normal e o anormal nas diferentes dimensões que compõem a vida social.

A possibilidade da invenção da norma ia ao encontro dos ideais da Liga, que - além da prevenção das doenças nervosas e mentais pelos princípios da higiene geral e do sistema nervoso, da melhoria e do cuidado aos egressos dos manicômios - visava à realização de um programa amplo de higiene mental e eugenética no domínio das atividades individuais, escolares, profissionais e sociais, o que incluía a difusão das normas de higiene neuropsíquicas para as classes populares (LBHM, 1925). ${ }^{7}$

Tendo também o objetivo de fazer circularem os saberes a respeito da higiene mental, a LBHM lançou, em 1925, o primeiro número dos Arquivos Brasileiros de Higiene Mental, afirmando

pretendem ser os Arquivos não só um repositório do que se publique sobre o assunto em nosso meio, ou alhures, mas também se possível, um núcleo de atração de prosélitos, no amplo domínio dessa higiene mental, que com justo direito aspira tornar-se 'a moral universal de amanhã' (LBHM, 1925).

Como porta-voz da moral universal do futuro, conforme veremos adiante, a LBHM foi herdeira de uma tradição que buscava consolidar a psiquiatria, desde o século XIX, como o dispositivo para o tratamento dos doentes mentais e, nessa direção, requeria do Estado a instalação de asilos científicos e criticava o tratamento dado aos doentes mentais, que eram abandonados à própria sorte e vagavam pelas cidades expostos a todo tipo de violência ou eram colocados em celas insalubres e submetidos aos castigos corporais nos porões das santas casas de Misericórdia e nas casas de Detenção (Resende, 2001; De Simoni, 2004; Salla, 2006). Ao mesmo tempo, a exigência do tratamento científico rompia com toda a mística em torno da loucura, o que provocaria de um lado condições favoráveis para a recepção dos saberes psicológicos e de outro a expansão do poder psiquiátrico.

No entanto, essa mesma tradição conduziu a psiquiatria a reproduzir o discurso teórico da psiquiatria francesa e com isso tornou inexistente a referência à realidade brasileira ou considerou-a apenas ocasionalmente (Machado et al., 1978).

Jacó-Vilela, Degani-Carneiro e Oliveira (2016) consideram que as características brasileiras no campo científico eram as de uma nação periférica onde se fazia presente a influência determinante das correntes de pensamento estrangeiras. Ao mesmo tempo, o país atravessava grandes mudanças sociais, inclusive a abolição da escravatura, que sustentavam no imaginário social a circulação de discursos a respeito da doença mental: "é uma época em que os males do Brasil são atribuídos tanto à presença do negro quanto - pior que tudo 
- à mestiçagem: em um amálgama de evolucionismo com a teoria da degenerescência de

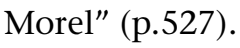

Além da reprodução de teorias estrangeiras, a psiquiatria se alinhava ao movimento da medicina social e da higiene pública, o que fazia entrar em cena uma série de mecanismos reguladores que implicavam não só a disciplinarização dos corpos, esfera individualizante do poder disciplinar, mas também regras de higiene que garantiriam a longevidade e a saúde da população: a higiene das famílias, os cuidados com as crianças, a escolaridade, os comportamentos e aptidões no trabalho, a mortalidade infantil etc. (LBHM, 1925).

Em função dessas articulações, do corpo individual à população em toda a sua multiplicidade, o elemento regulador que circula é a norma:

A norma é o que pode tanto se aplicar a um corpo que se quer disciplinar quanto a uma população que se quer regulamentar. ... A sociedade de normalização é uma sociedade em que se cruzam, conforme uma articulação ortogonal, a norma da disciplina e a norma da regulamentação (Foucault, 2005, p.302).

No entanto, o estabelecimento da norma, a definição e a representação da doença mental não deixavam de causar problemas no que se referia aos limites em relação à razão (Foucault, 2011). Seria a doença mental a impossibilidade de adaptação, o desajustamento social dos indivíduos às demandas da sociedade? Um recuo a um ponto de fixação do desenvolvimento? Uma inversão das funções psíquicas? Ilusão, erro, desregramento das paixões?

Assim, para a invenção da norma foi preciso um conjunto de outros termos e noções: funções, sínteses, conjuntos sintéticos e sínteses qualitativas ou quantitativas. Conforme ressaltou Radecki $\left(1925\right.$, p.21): ${ }^{8}$

Nos domínios da vida psíquica, é muitas vezes mais importante fixar a direção da procura da norma do que a própria norma. Evidentemente, como nas outras ciências, na psicologia certas indicações são fornecidas pela estatística, porque o que vai se repetindo as mais das vezes adquire, em certo sentido, o caráter de normalidade.

Nesse processo histórico,

A medicina mental, ela própria produto do desenvolvimento civilizatório, instaura a normalidade da conduta como critério de comparação entre individualidades, análise diferencial do caráter, hábitos, inclinações do indivíduo em seu meio familiar, em seu círculo de amizades, em sua vida profissional, em suas tendências políticas e convicções religiosas etc. (Machado et al., 1978, p.411).

A compreensão a respeito da normalidade da conduta posicionou a psicologia, desde o primeiro número dos Arquivos, como um dos saberes que forneceriam as bases para a compreensão e o apoio dos psiquiatras brasileiros no movimento de expansão da atuação psiquiátrica da LBHM para além dos muros asilares. Conforme o Estatuto da LBHM (1925, p.223), os Arquivos e outras publicações colaborariam com a organização "com que a Liga procurará difundir nas camadas populares as normas de higiene neuropsíquica já sancionadas pela unanimidade dos especialistas". O que estaria em acordo com a prevenção das "doenças nervosas e mentais pela observância dos princípios da higiene mental e em 
especial do sistema nervoso e a melhoria progressiva nos meios de assistir e tratar os doentes nervosos e mentais em asilos públicos, particulares e fora deles" (LBHM, 1925, p.223).

Enquanto um saber propedêutico, a psicologia colaboraria no estabelecimento dos limites entre o normal e o anormal no que se referia ao desenvolvimento infantil, à aprendizagem e à adaptação dos indivíduos desajustados.

Foucault (2008) não deixou de escrever sobre a psicologia em relação à prática psiquiátrica: a psicologia não poderia oferecer à psiquiatria o que a fisiologia possibilitou à medicina. No entanto, uma coisa parece certa: o estudo psicodinâmico sobre o desenvolvimento e o comportamento infantil, a aplicação de testes de inteligência, as clínicas e seções de ortofrenia (que ao mesmo tempo se caracterizavam como lugar de produção de saber sobre o anormal e também como espaço para a correção dos corpos) foram importantes para a construção do discurso psicológico que contribuiu, também no Brasil, para transformar profundamente nossas formas de perceber, sentir e agir, mesmo nos aspectos mais íntimos de nossa vida cotidiana (Paicheler-Harrous, 2018).

\section{Método}

É preciso, antes de seguir, delinear algumas perspectivas em torno da história da psicologia. Abordamos a constituição histórica dos saberes psicológicos inspirados nas proposições metodológicas apresentadas por Michel Foucault $(1999,2005,2008,2013)$.

Ainda que não possamos definir, em termos tradicionais, um método e uma teoria, Foucault nos aponta direcionamentos para uma análise genealógica acerca das formas de produção dos sujeitos modernos, indicando procedimentos técnicos, ferramentas para o desenvolvimento de descrições, análises e problematizações: "trata-se, isso sim, de uma techné que consiste numa forma muito singular de escutar a história" (Veiga-Neto, set.-dez. 2009, p.90).

A genealogia, conforme Faé (2004, p.413), escuta a história observando seus acasos e suas descontinuidades, desvios ou inversões que deram origem ao que existe e possui valor em nossos dias: "não existem a verdade e o ser, mas a exterioridade do acidente". Ainda nesse sentido, "se há algo a decifrar, algum segredo a desvendar, é que as coisas não têm essência, ou melhor, a suposta essência foi deliberadamente construída, a partir de situações específicas, contextualizadas histórica e socialmente" (p.413).

Esse empreendimento não significa um recuo infinito à origem dos discursos científicos e das práticas sociais emergentes na relação saber/poder. Não se trata de reencontrar as raízes de nossa identidade, mas, conforme escreveu Foucault (2011, p.35), de dissipá-las no sentido de desvelar os sistemas heterogêneos que, "sob a máscara do nosso eu, nos proíbem toda identidade".

Foucault (2005, p.14) define o método genealógico como o empreendimento de dessujeitar os saberes históricos capazes de oposição à coerção de um discurso teórico unitário, formal e científico: "É exatamente contra os efeitos de poder próprios de um discurso considerado científico que a genealogia deve travar o combate". A genealogia, nesse sentido, se opõe ao desdobramento meta-histórico das significações ideais e das teleologias indefinidas (Foucault, 2013). 
Nossa problematização implica compreender como os saberes psicológicos figuraram entre os elementos para a expansão do poder psiquiátrico nas primeiras décadas do século XX no Brasil e, portanto, como colaboraram para o contínuo processo de medicalização da sociedade. Este último exige fazer penetrar, nas mínimas dimensões da vida social, os discursos médicos. Ao mesmo tempo, quanto aos saberes psicológicos, esse processo também provocou sua vulgarização e sua expansão social, acontecimento que foi determinante para sua autonomização em relação à medicina e à pedagogia.

Após as delimitações de nossas perspectivas teórico-metodológicas e de nossa problematização, torna-se importante apontar os caminhos que trilhamos no sentido de seleção e análise. Para o desenvolvimento deste artigo selecionamos, a partir da leitura inicial de seus resumos, somente os textos originais publicados nos Arquivos Brasileiros de Higiene Mental, entre 1925 e 1947, que diretamente se referiam à psicologia, à psicometria, à psicologia experimental ou à psicologia aplicada.

A partir da leitura e da seleção dos artigos, trabalhamos com a descrição do papel da psicologia no âmbito da LBHM. Entre as diferentes temáticas que remetiam aos saberes psicológicos, e tendo em vista nossos atuais objetivos, estabelecemos dois campos de análise interrelacionados: a problemática sobre a delimitação do normal e do anormal e a aplicação dos testes psicológicos. ${ }^{9}$ Essa escolha se justifica pela compreensão de que ambos os campos se constituíam como fundamentais para os objetivos da LBHM, fosse em relação à delimitação do normal e do anormal, fosse quanto, partindo do estudo das funções, ao dinamismo psíquico, ao desenvolvimento infantil e à prevenção da doença mental.

O primeiro campo descreve e analisa as construções teóricas e as práticas que atribuíam à psicologia seu papel de ciência propedêutica para a psiquiatria; o segundo, intimamente relacionado ao primeiro, descreve as diretrizes e as dificuldades para a análise e aplicação dos procedimentos técnicos, assim como os elementos teóricos apresentados pela psicologia como fundamento para a constituição de diferentes práticas sociais, em especial no campo da educação.

\section{A invenção da norma: a psicologia e seu papel de ciência propedêutica para a psiquiatria}

O primeiro número dos Arquivos foi lançado em 1925. Já nas primeiras páginas seu editorial apresentava um amplo desafio à higiene mental: estabelecer princípios morais universais tendo como modelo o rápido avanço que vinha alcançando a higiene pública.

Considerando a importância da atividade psíquica, profundamente entrelaçada ao funcionamento físico do organismo humano, a higiene mental apresentava suas duas faces: o trabalho defensivo contra as causas da degeneração psíquica e a adaptação dos indivíduos ao meio físico e social. Esta última, conforme Fontenelle (1925, p.1), ${ }^{10}$ "é a higiene mental propriamente dita".

O problema da adaptação e do desajustamento social implicava considerar a doença mental uma perturbação na possibilidade de o indivíduo responder adequadamente às demandas da sociedade. Arthur Ramos (1903-1949), ${ }_{11}^{11}$ personagem importante nos campos da antropologia, da psicologia social e da psicanálise no Brasil, destacou que a psicose era 
o grau maior do desajustamento e propôs, no âmbito da LBHM, o atendimento de crianças como medida de prevenção e correção dos comportamentos indesejados: "A higiene mental deve velar a que não se acrescentem vivências negativas a uma personalidade mal formada. ... Deve dirigir-se a uma personalidade, corrigindo estruturas resultantes de vivências negativas" (Ramos, 1935, p.10).

A concepção de higiene no domínio mental reduz-se a um certo conjunto de ações práticas, com o fim de criar condições que possam facilitar o desenvolvimento psíquico dos indivíduos humanos, adaptando esse desenvolvimento às exigências sociais e à felicidade pessoal. Iniciando uma ação prática, cujo objeto é representado por um determinado domínio de fenômenos, devemos utilizar, em primeiro lugar, as noções recolhidas pelas ciências teóricas que do mesmo tratam (Radecki, 1925, p.12).

Nesse sentido, além de condicionar os interesses individuais aos determinantes e às demandas sociais, fazia-se necessário um saber que pudesse colaborar na construção de parâmetros e assim sustentar a delimitação entre o normal e o anormal, entre o desenvolvimento e o funcionamento complexo das estruturas psíquicas e suas alterações.

No movimento de expansão do campo psiquiátrico, conforme os ideais da LBHM, a psicologia seria sua base científica e atuaria de forma similar à fisiologia, que foi o fundamento da saúde física: forneceria elementos teóricos que auxiliariam a prática cotidiana dos médicos psiquiatras na efetivação da profilaxia da doença mental, o que implicava vigilância e controle do comportamento, além do tratamento adequado dos indivíduos em sua cura e adaptação (Fontenelle, 1925; Radecki, 1925).

A psicologia deveria corresponder a um duplo papel: caracterizar o desenvolvimento e o funcionamento normal conforme a história e as características dos indivíduos e produzir saberes que colaborassem para a construção de uma mentalidade desenvolvida corretamente por meio de experiências convenientes que se traduziriam no comportamento mais adequado e no que se poderia chamar de saúde mental.

Assim, o ajustamento do indivíduo às demandas da sociedade representaria sua saúde mental e, portanto, a capacidade de conciliação entre os interesses da sociedade e sua felicidade pessoal (Fontenelle, 1925; Radecki, 1925).

Esse discurso elege a infância como ponto central da ação profilática na LBHM. Entendida como período fundamental do desenvolvimento, desloca a criança para o centro de uma rede de práticas sociais, transformando-a no objeto privilegiado de um conjunto de técnicas que tinha, então, a função de vigiar e corrigir os movimentos e os desejos dos corpos. Ramos (1947), por exemplo, que dirigiu o Serviço de Ortofrenia e Higiene Mental, afirma que o conceito de liberdade vigiada foi condição essencial para o estabelecimento das regras de higiene mental no campo da educação.

Ainda que possamos pensar que essas ações eram parte de um movimento histórico de valorização da infância, tais medidas implicaram também a constituição de dispositivos que, a partir do novo lugar da criança, resultaram na elaboração de escalas, exames e testes para a correção do comportamento infantil e para a produção de sujeitos que deveriam corresponder, quando adultos, com comportamentos esperados, conseguindo um trabalho, constituindo uma família, vivendo a heterossexualidade e evitando as radicalidades 
políticas (Cardoso, 1925; Moreira, 1925; Campos, 1934; Roxo, 1947; Camargo, 1947). ${ }^{12}$ Essas idealizações morais repousavam em um discurso médico-científico. ${ }^{13}$

Considerando os aspectos psíquicos do desenvolvimento e tendo como paradigma a profilaxia, para os higienistas a educação se tornou o campo fundamental na correção dos comportamentos e na formação perfeita do futuro adulto. O que significava automatizar as boas normas de conduta que poderiam assegurar a saúde.

A doença mental não é mais que a falência da adaptação, e assim, a higiene mental necessita cuidar da inteligência como da conduta, educando-se a criança no pensamento generoso e no viver em harmonia com seus pequeninos companheiros. Naturalmente, haverá facilidade maior ou menor, de acordo com as tendências herdadas. Há os tarados, que precisam mil cuidados e assídua fiscalização, como há os que facilmente se submetem e rapidamente respondem ao trabalho educativo (Fontenelle, 1925, p.4).

De um lado, a educação, a educação sexual, a alimentação, a imaginação e o problema da delinquência se tornaram objetos privilegiados para a observação dos higienistas e direcionaram o olhar deles para a observação e o exame dos indivíduos, incluindo a virtualidade e propensão a uma possível condição que significasse o desajustamento dos sujeitos. Por outro, o corpo social e a defesa da sociedade em seu processo de modernização justificavam as campanhas contra o alcoolismo, a observação e exame dos imigrantes e as proposições sobre o controle de natalidade. ${ }^{14}$

A psiquiatria e a higiene mental pareciam ressaltar essas duas dimensões do poder médico e psiquiátrico, em expansão nas primeiras décadas do século XX: como poder disciplinar, individualiza os corpos no movimento de controle social e político relacionado à formação e estabilização da sociedade capitalista; ao mesmo tempo, na medida em que a degenerescência é uma ameaça ao corpo social, concilia o poder disciplinar com as estratégias biopolíticas para o controle das populações (Foucault, 2011).

Essas duas dimensões se entrelaçam na noção de doença mental, mas também em todo comportamento que se manifesta nos indivíduos e coloca em risco a ordem familiar e social.

Uma criança que se masturba demais será muito doente a vida toda: punição disciplinar no plano do corpo. Mas, ao mesmo tempo, uma sexualidade devassa, pervertida etc. tem efeitos no plano da população, uma vez que se supõe que aquele que foi devasso sexualmente tem uma hereditariedade, uma descendência que, ela também, vai ser perturbada, e isso durante gerações e gerações (Foucault, 2005, p.300).

As relações entre o individual e o social permitiram à psiquiatria a extensão de seu poder para muito além dos muros asilares e ambulatoriais. Os higienistas pretendiam, com o auxílio da psicologia, ${ }^{15}$ entrar nas mínimas esferas da vida social e íntima dos indivíduos: é preciso vigiar a imaginação, inserir as crianças em atividades práticas para que se evitem devaneios e o distanciamento da realidade; sobre a sexualidade, a psiquiatria poderia, conforme a idade, corrigir os efeitos viciosos da curiosidade sexual; à educação higiênica nas escolas caberia o exame sistemático do corpo e do espírito para a correção dos desvios; combater os excessos de sensibilidade dos filhos seria a obrigação de toda mãe que, pelos saberes psiquiátricos, conhecesse seus deveres. Para a família, sobretudo a mãe, era preciso combater os cuidados excessivos e a tolerância exagerada 
para que se preparasse a criança para o justo equilíbrio que permite seu total ajustamento (Fontenelle, 1925).

Essas dimensões da vigilância e da disciplinarização dos corpos, em especial os das crianças, estavam ligadas à ideia de dominação de seus instintos e à sua progressiva inserção em atividades práticas e de maior complexidade. A noção de excesso, na perspectiva dos higienistas, significava o afastamento do normal e a alteração do funcionamento das funções psíquicas. É o caso da imaginação, que em excesso provocaria na criança o afastamento da realidade e portanto sua proximidade da alienação mental.

O estudo das normas do desenvolvimento mental e do comportamento ganharia grande importância no projeto da LBHM, assim como a preparação de exames e inquéritos que revelassem as estruturas da personalidade e as características intelectuais. Radecki (1925), ainda que se referisse à dificuldade de observação direta do fenômeno psíquico - pois, para ele, a psicologia era diferente das ciências naturais; não tratava de fenômenos diretamente observados -, propunha que somente a exatidão do método permitiria a compreensão das partes isoladas dos indivíduos.

Além dos exames e dos inquéritos destacados por Fontenelle, Radecki (1925) enfatizou a importância e os problemas da aplicação dos testes, integrais ou parciais, sobretudo no que se referia ao isolamento das funções psíquicas e seu caráter quase sempre quantitativo, além dos possíveis erros de interpretação e método.

Esse aspecto também foi observado por Antipoff $(1930)^{16}$ durante a aplicação dos testes em crianças das escolas públicas de Minas Gerais. Então propôs que os testes deveriam ser complementados com outras formas de observação das crianças, como o desenho infantil. O mesmo problema é apontado por Ramos (1947), que, ao descrever o método de trabalho do Serviço de Ortofrenia e Higiene Mental, mencionava que para a análise do comportamento infantil eram importantes as técnicas de observação, o desenho infantil, as técnicas psicanalíticas e os testes psicológicos.

A aplicação complementar de diferentes técnicas para o exame das crianças deveria colaborar para a ampliação da observação dos comportamentos, a superação das análises e de resultados parciais e aumentar a exatidão dos diagnósticos. Nesse sentido, Radecki (1925), em sua crítica à aplicação e aos resultados parciais dos testes psicológicos, destacou o questionário elaborado para auxiliar os educadores na observação das crianças. $\mathrm{O}$ questionário era composto por 52 questões que tinham o propósito de evidenciar as características gerais dos escolares. As questões, que se dividiam conforme as funções do psiquismo (sensibilidade sensorial, atenção, discriminação, memória, imaginação, pensamento, vida afetiva e vontade) tinham o objetivo de ampliar e direcionar a observação para os fenômenos que deveriam ser percebidos.

Enquanto modalidade de observação dos indivíduos, a aplicação dos questionários constrói uma ritualística que sustenta a prática de professores e médicos. Percebemos que um aspecto parecia definitivo e em conformidade com o paradigma das ciências naturais, visto que estavam postos os sujeitos e os objetos: a criança, a família, os educadores, os psiquiatras e os médicos.

O problema tornava-se então, considerando o dinamismo psíquico e seu caráter quantitativo e qualitativo, estabelecer os limites entre o normal e o anormal. No entanto, 
a norma não deveria se fixar de todo nos critérios quantitativos, mas, qualitativamente, deveria considerar também o indivíduo em sua virtualidade, as características e aptidões mentais de cada indivíduo e de cada grupo social. ${ }^{17}$ Seguindo esses apontamentos e reafirmando uma vez mais o papel da psicologia, Roxo (1925), ao escrever sobre as causas da doença mental, considerou que a psicologia experimental poderia apresentar resultados que auxiliassem não apenas na compreensão do desenvolvimento, mas também a respeito das escalas, da divisão de classes e da correção dos hábitos que poderiam levar à degeneração. O que acarretaria considerar, segundo afirmou Pernambucano Filho (1930) cinco anos mais tarde, os aspectos psicossociais, como a sugestão e o contágio, implicados na enfermidade mental.

Conforme escreveu Caponi (2009), ainda nas últimas décadas do século XIX o corpo deixou de ser pensado somente a partir de tecidos e órgãos. Na psiquiatria, embora existam as categorias e as classificações diagnósticas, antes de tudo a questão que se coloca é binária: saber se o paciente é ou não louco.

\section{Testes, exames e funções: os procedimentos técnicos e os elementos teóricos da psicologia}

A LBHM, segundo relato de Leme Lopes (1932a, p.99), no desenvolvimento de suas ações, cogitou a abertura de um Laboratório de Psicologia, o que ocorreu em 1926, para que este pudesse fornecer os subsídios "indispensáveis à sua atuação profilático-social".

O laboratório deveria corresponder aos fins estabelecidos pela LBHM no sentido de fornecer subsídios teóricos para a adaptação e a prevenção à doença mental, o que resultaria em compreender as características e aptidões mentais dos indivíduos. Nesse sentido, dedicarse-ia a construir saberes que fundamentariam práticas também no campo do trabalho e da orientação profissional.

A primeira dificuldade talvez fosse a ausência de psicólogos para a direção do laboratório, o que fez a LBHM recorrer ao francês Henri Pièron, que indicou Alfred Fessard, e a Mme. A.B. Fessard, que, "em três meses de permanência no Rio, foram incansáveis na preparação técnica de quantas condições houvesse capazes de garantir o êxito da missão que lhes fora confiada" (Lopes, 1932a, p.99).

Sob sua direção, o laboratório iniciou as atividades no segundo semestre de 1926, e, desde o início, os trabalhos experimentais se desenvolveram em três sentidos: constituindo-se como centro de pesquisa com o objetivo de fornecer suporte teórico à psiquiatria; adaptando às condições regionais as provas já existentes ou elaborando novos testes para a avaliação das funções psíquicas e do comportamento; e contribuindo para a formação teórico-prática no aprendizado da psicologia (Lopes, 1932a).

A formação em psicologia foi um dos interesses da LBHM, sendo que no espaço do laboratório foram realizados cursos de psicologia experimental, psicometria e sobre as bases fisiológicas do comportamento e a psicanálise. ${ }^{18}$

Um dos editoriais dos Arquivos, a LBHM (1930, p. 311) reafirmava a relação entre a psicologia e a higiene mental, em especial a contribuição dos saberes psicológicos ao campo psiquiátrico: 
São essas técnicas que, mais do que quaisquer outras, permitirão ao especialista a justa avaliação das mentalidades normais, trabalho prévio imprescindível a uma série de aplicações específicas de higiene mental, em sentido estrito, quer dizer concernentes aos indivíduos sãos de espírito: orientação profissional, seleção psicológica dos escolares, saúde mental dos operários etc.

O funcionamento do laboratório parece ter seguido esses direcionamentos práticos que correspondiam tanto à ideia de modernização quanto à de prevenção das doenças mentais. Esses elementos, constituintes da LBHM, que provocavam o distanciamento dos psiquiatras em relação ao saber religioso e leigo sobre a doença mental, por outro lado se harmonizavam com os preconceitos e contradições que a própria noção de modernização do país abrigava.

No interior da LBHM, todo o trabalho de revisão e estalonagem dos testes seguiu essa diretriz que tinha como objetivo a educação das crianças e a higiene mental no trabalho. Ambos significavam a adaptação dos indivíduos por meio da identificação de suas características mentais e da profilaxia das doenças mentais relacionadas à aprendizagem e ao trabalho.

Conforme avaliado por Leme Lopes (1932b) o laboratório se dedicou à organização completa do material de Binet-Terman, à tradução e organização do material do exame psicográfico da inteligência de Vermeylen, à tradução e aplicação dos testes de nível motor de Ozeretzky e à organização e ao estudo de trabalhos que se voltavam para a avaliação sobre a discriminação das cores no jardim da infância, para determinar a acuidade visomotora, entre outras atividades.

Da continuidade do esforço dos que trabalham em psicologia dependerá por certo muito do êxito desses estudos, tanto mais úteis quanto mais descurados têm sido em nosso meio. Um campo enorme se abre ante nós - em que quase tudo está ainda por realizar (Lopes, 1932b, p.104).

Ainda assim, a psicologia enfrentou o ceticismo a respeito de sua eficácia e cientificidade. A crítica aos testes, reconhecidos como instrumentos importantes para o psicodiagnóstico, denunciavam a parcialidade de seus resultados, sobretudo por não avaliar qualitativamente o funcionamento psíquico.

Lopes e Fialho (1929), ${ }^{19}$ sem diferenciar os testes psicológicos e pedagógicos, defendiam que sua qualidade estava em seu valor universal e na possibilidade de sua aplicação na seleção de alunos para a formação de classes homogêneas. Por isso insistiam na necessidade de reformar e adaptar as escalas à realidade brasileira, assim como distribuir os diferentes testes ao longo das faixas etárias.

A LBHM noticiava os resultados das aplicações de testes nos estados de Minas Gerais, Rio de Janeiro e Pernambuco. De maneira geral, as pontuações dos testes de inteligência, no processo de adaptação à realidade brasileira, indicavam a necessidade de novas aplicações e estudos, pois apresentavam resultados ainda pouco representativos (Frossard, 1930; Pernambucano, Barreto, 1930). ${ }^{20}$ No entanto, os resultados, mesmo que de forma precária, possibilitaram a comparação entre as pontuações alcançadas no Brasil e as obtidas na Europa. 
A psicologia se ocupava com a avaliação da evolução mental e física das crianças, e os resultados das escalas e testes deveriam fornecer as normas quantitativas e qualitativas para as diferentes idades. Conforme Antipoff (1930, p.230),

o desenvolvimento mental é estudado - pelos testes da inteligência geral, e por múltiplos testes de aptidões (motricidade, atenção, memória, observação, testemunho etc.) ... Permitirá tal pesquisa, ainda que grosso modo, delinear a mentalidade da criança brasileira, pelo menos da do Brasil central, na presente época. Repetida várias vezes, dará ensejo a que se acompanhe a evolução da mentalidade infantil em diferentes épocas e sob diversas orientações educativas.

Pernambucano (1930), ao escrever sobre a psicologia em Pernambuco, relatou o início de seu trabalho de revisão da escala Binet-Simon. Tendo optado por trabalhar com a escala revista por Terman nos EUA, estabeleceu as instruções para seu uso. As primeiras aplicações do teste não pareciam conclusivas, e Pernambucano sinalizava a necessidade de continuidade das pesquisas e a interferência de fatores sociais nos resultados obtidos. Ainda assim, as aplicações dos testes em diferentes locais do país permitiriam a comparação dos resultados, o que não nos parece ter sido efetivado de maneira ampla naquele momento.

Do mesmo modo, Pernambucano e Barreto (1930) se dedicaram a revisar o teste das cem questões de Ballard, que poderia, segundo os autores, colaborar na formação de classes homogêneas, porém exigiam novas pesquisas para a validação de seus resultados.

A psicologia na LBHM, com esse esforço de revisão e adaptação dos testes, tinha como objetivo colaborar não só para a formação de classes escolares, ainda que isso fosse importante para os autores que apontamos até aqui, mas para a identificação das aptidões, orientação e adaptação dos indivíduos ao trabalho.

Nesse sentido, Antipoff (1930) escreveu que um dos problemas mais importantes para a psicologia era a evolução mental e física das crianças nas várias faixas etárias. Os inquéritos e testes teriam por fim fornecer normas quantitativas e qualitativas para as diferentes idades. No entanto, o estudo da criança não se limitaria à aplicação dos testes: "A psicologia, para nós, é antes de tudo a ciência da conduta humana, e esta só poderá ser estudada nas reações dos vários excitantes exteriores, que atuam sobre o indivíduo, ou sobre um grupo de indivíduos, dentro de um meio dado" (p.230).

A psicologia da criança, apoiada pelas observações diretas, a aplicação de testes variados, a observação dos desenhos e dos jogos infantis, possibilitaria conhecer intimamente os escolares e os múltiplos fatores da aprendizagem, incluindo as características de personalidade e abrindo assim uma nova perspectiva na ritualística de classificação e diagnóstico.

A necessidade de seriação dos mentalmente anormais ... é uma pesquisa sutilíssima e somente aos psiquiatras-pedagogos é dado descobrir qual a classe de tal ou qual atraso mental, qual o seu deficit mental para ser possível individualizar a educação corretiva e terapêutica adequada (Cavalcante, 1943, p.5). ${ }^{21}$

O psiquiatra-pedagogo, o médico-psicólogo, entre as crianças repetentes, diferentemente dos pais e educadores, seria o único a descobrir "o defeito afetivo". Essa descoberta tinha também um efeito prático: "a classificação dos tipos de atrasados mentais é imprescindível na organização das classes especiais" (Cavalcante, 1943, p.5). 
A psicologia experimental aplicada à educação destacava-se também como instrumento de investigação dos aspectos psicossociais relacionados à aprendizagem e para o desenvolvimento de material científico que colaboraria para a coordenação racional dos processos educativos (Lopes, 1931). ${ }^{22}$ Fatores diversos, como os recursos físicos e a atitude das populações, as relações com a imigração e a preservação dos espaços compartilhados pela comunidade são considerados nos processos de aprendizagem, e a proposição de um inventário para a sua análise ganha destaque.

Lopes se dedicou a escrever um longo artigo sobre a adaptação e as normas de aplicação do teste Binet-Terman, recomendando também a inclusão de um aluno de séries mais avançadas como assistente do examinador. Mas, antes de tudo, descreveu um conjunto de procedimentos que antecediam à própria aplicação: o examinador tem que conquistar a confiança do examinando e vencer a sua timidez (Lopes, 1931). Elogiar a participação da criança, não demonstrar em sua expressão qualquer desagrado ou fadiga com as respostas produzidas e observar a ordem de apresentação dos testes são elementos fundamentais para a obtenção de melhores resultados, que possibilitariam a identificação das deficiências relacionadas ao desenvolvimento intelectual infantil.

É importante notar que os resultados das aplicações dos testes, exames e inquéritos alcançaram a clínica psiquiátrica não apenas no trabalho com as crianças, mas no que se referia a uma abordagem que interviesse nas causas afetivas e ambientais que provocavam o sofrimento psíquico (Roxo, 1944; Silva, 1939). ${ }^{23}$

Para além do campo da educação, ainda que esse tenha absorvido muitas de suas forças, a psicologia também colaborou na abertura de novos ambulatórios de higiene mental e na compreensão geral da doença mental como resultado de uma interação de causas biológicas, afetivas e sociais.

De qualquer forma, é na suposta ruptura com a noção mítico-religiosa sobre a origem da doença mental que se possibilita a consolidação dos saberes psi no país e a afirmação da norma enquanto reguladora dos modos de vida implicados no avanço da industrialização e do capitalismo.

\section{Considerações finais}

Ainda nos anos 1970, ao escrever sobre a relação entre a loucura, a sociedade e os saberes psicológicos, Foucault (2011, p.266) afirmou que sua crítica não tinha a intenção de ser uma negação da psiquiatria, e sim visava ao processo de medicalização do louco que se produziu por razões essencialmente econômicas e sociais: "foi assim que o louco foi identificado ao doente mental e que uma entidade chamada doença mental foi descoberta e desenvolvida".

No interior de sua crítica, havia ainda uma reflexão sobre a prática científica e a produção da verdade acerca da doença mental, incluindo sua potencialidade adormecida nos corpos. Nesse sentido, não deixou de se dedicar a compreender e descrever a ritualística que produziria o sujeito psiquiátrico e a sua verdade íntima.

Por sua vez, a produção de verdade demandaria sua própria geografia e não se efetivaria somente pela mediação de instrumentos, mas pelos rituais que provoca em torno dos 
sujeitos e pelas relações de poder que, sobretudo em relação ao poder psiquiátrico, carregam aspectos normativos (Foucault, 2011).

Ao mesmo tempo, Foucault (2011) ressaltou que, a partir do século XIX, desenvolveuse em torno da instituição judiciária um conjunto de poderes laterais que tinham como principal tarefa enquadrar os indivíduos ao longo de sua existência: instituições pedagógicas, como a escola, psicológicas ou psiquiátricas, como os hospitais e os asilos, a polícia etc. Toda essa rede de poder, que o filósofo chamou de ortopedia social, indicava aspectos particulares de um tipo de sociedade que chamou de disciplinar, na qual o exame mental seria uma tecnologia para a análise, a construção da verdade e a disciplinarização dos indivíduos.

Essa é a base do poder, a forma de saber-poder que vai fazer surgirem as ciências humanas. E nesse movimento de redistribuição da épistémè, a psicologia "é fundamentalmente um estudo do homem em termos de funções e normas" (Foucault, 2007, p.495).

É na superfície da projeção da biologia que o homem aparece como um ser que tem funções - que recebe estímulos (fisiológicos, mas também sociais, inter-humanos, culturais), que responde a eles, que se adapta, evolui, submete-se às exigências do meio, harmoniza-se com as modificações que ele impõe, busca apagar os desequilíbrios, age segundo regularidades, tem, em suma, condições de existência e a possibilidade de encontrar normas médias que lhe permitem exercer suas funções (Foucault, 2007, p.494).

A psicologia, no âmbito da LBHM, figurou como saber que possibilitou a extensão do poder psiquiátrico, principalmente nos campos da educação e do trabalho. Forneceu suporte, como saber individualizante e em sua articulação com a higiene mental e em sua interseção com a sociologia, na construção de políticas sobre o corpo social.

No movimento de expansão do poder psiquiátrico, a psicologia também encontrou a possibilidade de sua disseminação e vulgarização. Isso não aconteceu sem as contradições de seu tempo, inclusive no que se refere aos componentes racistas do higienismo e da posição de saber e técnica disciplinar.

Na medida em que possibilitava aos higienistas a extensão de seu saber e de suas práticas, agora além dos muros asilares, a psicologia fazia existir uma verdade que repousava silenciosa no interior dos corpos: tratava-se de, como escreveu o filósofo francês:

fazer existir como doença ou eventualmente como não doença os motivos dados para um internamento ou uma intervenção psiquiátrica possível. ... é que o problema que estava para ser resolvido na atividade psiquiátrica não era tanto, não era o saber primeiramente de saber se determinado comportamento, determinada maneira de falar, determinado tipo de alusão, determinada categoria de alucinação se referiam a esta ou aquela forma de lesão: o problema era saber se dizer determinada coisa, comportar-se de determinada maneira, ouvir determinada voz etc., se isso era ou não era loucura (Foucault, 2005, p.347).

O interesse sobre a vida, o desenvolvimento mental e os processos grupais não só tornava possível a extensão do discurso psiquiátrico como sinalizava a possibilidade de encontro da verdade acerca de cada e todo indivíduo, e a consolidação de um projeto para a sociedade em consonância com a modernização do país, a modelagem do caráter 
nacional e o desenvolvimento do capitalismo. Assim, a emergência do sujeito psicológico estava atrelada aos princípios disciplinares da sociedade industrial.

A LBHM, partindo do discurso e da preocupação a respeito da identidade e do caráter brasileiro, incorporou diferentes saberes, como a psicanálise e a eugenia. Sobre a psicologia, encontrou apoio na invenção das normas que delimitariam suas ações no campo da higiene mental e na profilaxia das doenças mentais.

Nesse movimento, em um amplo sentido, a psicologia contribuiu com a psiquiatria também na regulagem sobre quem poderia falar e o que se poderia dizer e fazer quanto à doença mental, à infância, à sexualidade etc. O psiquiatra-pedagogo ou o médicopsicólogo são os que podem diagnosticar e tratar as diferentes formas de adoecimento e desajustamento. A psicologia, considerada pelos psiquiatras da LBHM saber propedêutico, também foi submetida à ordenação do discurso psiquiátrico.

Poderíamos considerar que a ordenação imposta pelo discurso psiquiátrico alcança nossos dias, ainda que revestido de outros discursos e apoiado em novos saberes, como o avanço da indústria farmacológica e a neuropsiquiatria? As tensões em torno das práticas no campo da saúde e da saúde mental e a tentativa de regulação do projeto de lei que ficou conhecido como Ato Médico seriam novas formas históricas da centralidade pretendida pelo saber médico-psiquiátrico?

Sobre a psicologia brasileira, seu futuro não estaria em considerar seriamente as contradições e as controvérsias presentes desde a sua emergência?

\section{NOTAS}

${ }^{1}$ Gustavo Köhler Riedel (1887-1934) iniciou seus estudos na Faculdade de Medicina de Porto Alegre em 1903. Em 1910, tornou-se alienista adjunto do Hospício Nacional dos Alienados, e em 1923 foi nomeado diretor-geral da Assistência a Psicopatas do Distrito Federal. No mesmo ano, fundou e foi o primeiro presidente da LBHM (Carvalho, 2001).

2 Juliano Moreira (1873-1933) nasceu em Salvador. Aos 13 anos, matriculou-se como interno da Faculdade de Medicina da Bahia, onde se graduou em 1891 com a monografia Sífilis maligna precoce. Em 1899, como catedrático da Faculdade de Medicina da Bahia, realizou conferências em que divulgava as ideias de Freud e tornou-se um dos precursores do pensamento freudiano no Brasil (Venancio, 2001).

${ }^{3}$ Henrique de Brito Belford Roxo (1877-1969) doutorou-se na Faculdade de Medicina do Rio de Janeiro em 1901 e defendeu a tese intitulada Duração dos atos psíquicos elementares nos alienados, em que propôs que a psiquiatria tomasse a psicologia como saber propedêutico. Frequentou as clínicas psiquiátricas de Heidelberg e de München, onde encontrou Emil Kraepelin. Foi membro da Sociedade Brasileira de Psiquiatria, Neurologia e Ciências Afins, professor catedrático de psiquiatria da Faculdade de Medicina do Rio de Janeiro, diretor do Pavilhão de Observações do Hospício Nacional de Alienados e, posteriormente, do Instituto de Psiquiatria da Universidade do Brasil.

${ }^{4}$ Alfred Fessard (1900-1982) foi colaborador de Henri Piéron. Na França, dirigiu o Laboratório de Psicologia da Sensação e Psicologia Experimental (Fraisse, 1982).

${ }^{5}$ Plínio Olinto (1886-1956) formou-se na Faculdade de Medicina do Rio de Janeiro. Ministrou cursos e dirigiu o Laboratório de Psicologia da LBHM. Escreveu diversos textos sobre psicologia e, em 1944, foi autor de um dos primeiros trabalhos sobre história da psicologia: A psicologia experimental no Brasil.

${ }^{6}$ Maria Brasília Leme Lopes (1909-1996) foi professora normalista e titular da Seção de Psicologia Aplicada da Liga Brasileira de Higiene Mental.

${ }^{7}$ Esses ideais não deixaram de se implicar no processo de embranquecimento da população, proposição que ganhou a aderência e participação dos médicos brasileiros que, conforme descrito por Schwarcz (2014), percebiam a mestiçagem como um dos fatores que dificultavam a modernização do país. 


\begin{abstract}
${ }^{8}$ Waclaw Radecki (1887-1953) foi diretor do Laboratório de Psicologia na Colônia de Alienados do Engenho de Dentro, psicologista da Fundação Gaffreé-Guinle e da Liga Brasileira de Higiene Mental. Também foi professor e diretor da Faculdade de Psicologia da Universidade Livre de Varsóvia.
\end{abstract}

${ }^{9}$ É importante ressaltar que os Arquivos apresentam diversas outras temáticas que poderão interessar aos historiadores da psicologia no Brasil. A relação entre a higiene mental e a psicanálise, o problema da delinquência e o dinamismo psíquico, a questão do alcoolismo e da degeneração, a imigração e a raça etc. são temáticas emergentes na leitura dos Arquivos. Nosso projeto futuro é trabalhar nos escritos de Arthur Ramos sobre a psicanálise na LBHM.

${ }^{10}$ José Paranhos Fontenelle (1885-1975) foi docente efetivo de Higiene Mental da Escola Normal do Distrito Federal. Vice-presidente da Sociedade Brasileira de Higiene e membro efetivo da Seção de Puericultura e Higiene Infantil da LBHM.

${ }^{11}$ Arthur Ramos (1903-1949) estudou na Faculdade de Medicina da Bahia. Possui extensa obra, que abrange as áreas de psiquiatria, psicanálise, psicologia social e antropologia. Participou de diversas instituições acadêmicas e assistenciais e, atendendo ao convite de Afrânio Peixoto, dirigiu a Seção Técnica de Ortofrenia e Higiene Mental, no Rio de Janeiro (Nascimento, 2018).

${ }^{12}$ Murilo Campos foi docente da Clínica Psiquiátrica da Faculdade de Medicina da Universidade do Rio de Janeiro e membro do Conselho Consultor da LBHM. Oswaldo Camargo foi fellow do Commonwealth Fund e do Institute of Inter-American Affairs.

${ }^{13}$ A imigração, inclusive a chegada de ideais considerados radicais, tornou-se um problema tratado pelos higienistas. A preocupação sobre a entrada dos imigrantes no país implicava propostas que elaborassem critérios de seleção para a permissão de entrada no país, principalmente de raças não brancas. Os estrangeiros, segundo Oliveira (1932), durante as décadas de 1920 e 1930 ocupavam cerca de $20 \%$ das vagas nos manicômios nacionais. O mesmo Oliveira (1932), que se denominava eugenista, ainda que apresentasse a alta prevalência do alcoolismo entre os portugueses, argumentava que as maiores restrições deveriam ser empregadas contra os imigrantes vindos da Ásia e da Ásia Menor, já que, segundo o autor, ainda nos primeiros meses de sua estada a doença mental se revelava. Ao mesmo tempo, defendia a existência de uma vigilância moral.

${ }^{14}$ Médico que integrou a LBHM, Farani (1931, p.169) escreveu sobre como evitar a prole de degenerados, correspondente ao ideal de proteção ao corpo social: "É bem de ver que não se pode tolerar hoje o decreto espartano de eliminar degenerados. A pena de morte também tem seus requisitos legais, dentre os quais não figura a degeneração mental. Como agir então? Impedindo o nascimento do degenerado".

${ }^{15}$ Assim como os saberes psicanalíticos e eugênicos.

${ }^{16}$ Helena Wladimirna Antipoff (1892-1974) nasceu em Grodno, na Rússia. Em 1929, veio para o Brasil a convite do governo do estado de Minas Gerais e passou a atuar como professora de psicologia na Escola de Aperfeiçoamento de Professores. Em 1932, fundou a Sociedade Pestalozzi de Belo Horizonte.

${ }^{17}$ Como exemplo disso podemos observar que, em Introdução à psicologia social, Ramos (1936), que foi filiado a LBHM, escreveu que o objeto privilegiado da emergente ciência seria a noção de personalidade. Para isso, apoiou-se em Social psychology, de Young (1945), no qual os estudos dos hábitos, das atitudes, dos preconceitos, da linguagem e das interações sociais tornavam possível a compreensão da personalidade, pois revelariam a emergência do eu social a partir do ato e das interações sociais.

${ }^{18}$ Em 1927 foi realizado um breve curso de psicologia experimental para alunas da Escola Normal. No mesmo período, o Laboratório contou com a colaboração de Manoel Bonfim, principalmente sobre os aspectos técnicos de seu funcionamento. Dois anos mais tarde, o laboratório realizou o que se chamou de demonstrações práticas para enfermeiras do Curso de Higiene Mental. O curso Psicologia e Técnica Psicológica, em 1931, contou com a participação de Ulysses Pernambucano, Helena Antipoff e Maurício Medeiros. Júlio Porto-Carrero encarregou-se de três conferências acerca dos métodos psicanalíticos, da teoria da psicanálise e das aplicações da psicanálise na educação. No mesmo ano, foi realizado o curso de Introdução Fisiológica ao Estudo da Psicologia, no qual foram expostas as bases fisiológicas pelas quais se poderia interpretar o funcionamento psíquico.

${ }^{19}$ Idalina de Abreu Fialho foi professora do Instituto Benjamin Constant e titular da Seção de Psicologia da LBHM.

${ }^{20}$ Nicolar Cortat Frossard foi professora municipal e titular da Seção de Psicologia Aplicada e Psicanálise da LBHM. Ulisses Pernambucano (1892-1943), médico, foi professor da Faculdade de Medicina e do Ginásio do Recife; diretor do Instituto de Orientação Profissional e delegado regional da LBHM. Anita Paes Barreto (1907-2003) foi professora da Escola Normal e primeira auxiliar do Instituto de Orientação Profissional. 
${ }^{21}$ Adalberto de Lira Cavalcante, ex-diretor do Hospital de Alienados de Recife, técnico de saúde escolar da Prefeitura do Distrito Federal.

22 Ernani Lopes (1875-1975), psiquiatra da Assistência a Psicopatas, membro honorário da Academia Nacional de Medicina e da Liga Argentina de Higiene Mental.

${ }^{23}$ Antonio Carlos Pacheco e Silva (1898-1988) foi assistente de Franco da Rocha, a quem sucedeu na direção do Hospício do Juqueri e na cátedra de psiquiatria da Faculdade de Medicina de São Paulo. Criou o manicômio Judiciário de São Paulo em 1927, foi membro da LBHM e criou a Liga Paulista de Higiene Mental, com sede no Juqueri. Vale lembrar que o mesmo foi simpático às teorias de aperfeiçoamento da raça e da educação eugênica.

\section{REFERÊNCIAS}

ANTIPOFF, Helena.

A psicologia na Escola de Aperfeiçoamento de Belo Horizonte. Arquivos Brasileiros de Higiene Mental, v.3, n.7, p.226-243. 1930.

ANTUNES, Mitsuko Aparecida Makino. A psicologia no Brasil: leitura histórica sobre sua constituição. São Paulo: Marco Editora; Educ. 2007.

CAMARGO, Oswaldo.

Clínicas de orientação infantil. Arquivos Brasileiros de Higiene Mental, v.18, n.1, p.14-30. 1947.

CAMPOS, Murillo.

O filho único e a higiene mental. Arquivos

Brasileiros de Higiene Mental, v.7, n.1, p.3-17. 1934.

CAPONI, Sandra.

Michel Foucault e a persistência do poder psiquiátrico. Ciência e Saúde Coletiva, v.14, n.1, p.95-103. 2009.

CARDOSO, Álvaro.

Subsídios à legislação sobre imigração: meios de impedir o ingresso dos deficientes morais. Arquivos Brasileiros de Higiene Mental, v.1, n.1, p.141-146. 1925.

CARVALHO, Alexandre Magno Teixeira de. Gustavo Köhler Riedel. In: Campos, Regina Helena de Freitas. Dicionário biográfico da psicologia no Brasil: pioneiros. Rio de Janeiro: Imago. 2001.

CAVALCANTE, Adalberto.

Crianças anormais. Arquivos Brasileiros de Higiene Mental, v.7, n.1, p.17-20. 1943.

DE SIMONI, Luiz Vicente.

Importância e necessidade da criação de um manicômio ou estabelecimento especial para o tratamento dos alienados. Revista Latinoamericana de Psicopatologia Fundamental, v.12, n.1, p.142-159. 1a. ed. 1838. 2004.

FAÉ, Rogério.

A genealogia em Foucault. Psicologia em Estudo, v.9, n.3, p.409-416. 2004.
FARANI, Alberto.

Como evitar as proles degeneradas. Arquivos

Brasileiros de Higiene Mental, v.4, n.3, p.169-179. 1931.

FONTENELLE, José Paranhos.

Higiene mental e educação. Arquivos Brasileiros de Higiene Mental, v.1, n.1, p.1-10. 1925.

FOUCAULT, Michel.

Nietzsche, a genealogia, história. In: Foucault, Michel. Organização de Manoel Barros da Motta. Arqueologia das ciências e história dos sistemas de pensamento: ditos e escritos 2. Rio de Janeiro: Forense Universitária. 2013.

FOUCAULT, Michel.

A verdade e as formas jurídicas. Rio de Janeiro: Nau; PUC-Rio. 2011.

FOUCAULT, Michel.

Nascimento da biopolítica. São Paulo: Martins Fontes. 2008.

FOUCAULT, Michel.

A palavra e as coisas. São Paulo: Martins Fontes. 2007.

FOUCAULT, Michel.

Em defesa da sociedade. São Paulo: Martins Fontes. 2005.

FOUCAULT, Michel.

História da sexualidade I: a vontade de saber. Rio de Janeiro: Graal. 1999.

FRAISSE, Paul.

Alfred Fessard. L'Année Psychologique, v.82, n.2, p.545-546. 1982.

FROSSARD, Nicolar Cortat.

Os testes de Binet em nossas escolas. Arquivos

Brasileiros de Higiene Mental, v.3, n.4, p.127-131. 1930.

JACÓ-VILELA, Ana Maria; DEGANI-CARNEIRO, Filipe; OLIVEIRA, Dayse de Marie.

A formação da psicologia social como campo científico no Brasil. Psicologia e Sociedade, v.28, n.3, p.526-536. 2016. 
LBHM.

Liga Brasileira de Higiene Mental. Editorial. Arquivos Brasileiros de Higiene Mental, v.3, n.9, p.311-313. 1930.

\section{LBHM.}

Liga Brasileira de Higiene Mental. Editorial. Arquivos Brasileiros de Higiene Mental, v.1, n.1, p.1. 1925.

LOPES, Ernani.

Subsídios para a adaptação brasileira dos testes de Binet-Terman. Arquivos Brasileiros de Higiene Mental, v.4, n.1, p.17-53. 1931.

LOPES, Maria Brasília Leme.

Laboratório de psicologia. Arquivos Brasileiros de Higiene Mental, v.5, n.2, p.99-109. 1932a.

LOPES, Maria Brasília Leme.

A atenção concentrada explorada pelo teste de cancelamento. Arquivos Brasileiros de Higiene Mental, v.5, n.2, p.41-62. 1932b.

LOPES, Maria Brasília Leme; FIALHO, Idalina de Abreu.

Sugestões para o emprego dos testes. Arquivos Brasileiros de Higiene Mental, v.2, n.2, p.68-77. 1929.

LOURENÇO FILHO, Manoel Bergstrom. A psicologia no Brasil. In: Antunes, Mitsuko Aparecida Makino (Org.). História da psicologia no Brasil: primeiros ensaios. Rio de Janeiro: Eduerj/Conselho Federal de Psicologia. 2004.

MACHADO, Roberto et al.

Danação da norma: medicina social e constituição da psiquiatria no Brasil. Rio de Janeiro: Graal. 1978.

\section{MASSIMI, Marina.}

História da psicologia brasileira: da época colonial até 1934. São Paulo: Editora Pedagógica e Universitária. 1990.

MOREIRA, Juliano.

A seleção individual de imigrantes no programa de higiene mental. Arquivos Brasileiros de Higiene Mental, v.1, n.1, p.109-117. 1925.

NASCIMENTO, Fernando A. Figueira do. Arthur Ramos: perspectivas de uma trajetória. Boletim da Sociedade Brasileira de História da Ciência, v.17. 2018.

OLIVEIRA, Xavier.

Da profilaxia mental dos imigrantes. Arquivos Brasileiros de Higiene Mental, v.5, n.1, p.16-38. 1932.

PAICHELER-HARROUS, Geneviève.

A invenção da psicologia moderna. São Paulo: Benjamin. 2018.

PERNAMBUCANO FILHO, Pedro.

Alguns aspectos sociais da morfinomania.
Arquivos Brasileiros de Higiene Mental, v.3, n.2, p.37-43. 1930.

PERNAMBUCANO, Ulysses.

A psicologia em Pernambuco. Arquivos Brasileiros de Higiene Mental, v.3, n.9, p.85-312. 1930.

PERNAMBUCANO, Ulysses; BARRETO, Anita

Paes.

Ensaio de aplicação do teste das cem questões de Ballard. Arquivos Brasileiros de Higiene Mental, v.3, n.9, p.313-346. 1930.

RADECKI, Waclaw.

Higiene mental da criança baseada sobre as leis da psicologia. Arquivos Brasileiros de Higiene Mental, v.1, n.1, p.11-89. 1925.

RAMOS, Arthur.

A criança problema. Rio de Janeiro: Livraria Editora Casa do Estudante do Brasil. 1947.

RAMOS, Arthur.

Introdução à psicologia social. São Paulo: Ed. José Olympio. 1936.

RAMOS, Arthur.

Educação física elementar (sob o ponto de vista da caractereologia). Arquivos Brasileiros de Higiene Mental, v.8, n.1, p.3-12. 1935.

RESENDE, Heitor.

Política de Saúde Mental no Brasil: uma visão histórica. In: Tundis, Silvério Almeida; Costa, Nilson do Rosário (Org.). Cidadania e loucura: políticas de saúde mental no Brasil. Petrópolis: Vozes. 2001.

ROXO, Henrique.

Problemas de higiene mental. Arquivos Brasileiros de Higiene Mental, v.18, n.1, p.11-13. 1947.

ROXO, Henrique.

Ideias atuais sobre psiquiatria. Arquivos Brasileiros de Higiene Mental, v.15, n.1, p.9-15. 1944.

ROXO, Henrique.

Higiene mental. Arquivos Brasileiros de Higiene Mental, v.1, n.2, p.1-9. 1925.

SALLA, Fernando.

As prisões em São Paulo. São Paulo: Annablume; Fapesp. 2006.

SCHWARCZ, Lilian Moritz.

O espetáculo das raças: cientistas, instituições e questão racial no Brasil, 1870-1930. São Paulo: Companhia das Letras. 2014.

SILVA, Antonio Carlos Pacheco e.

Rudimentos de higiene mental. Arquivos Brasileiros de Higiene Mental, v.12, n.3, p.52-60. 1939.

SOARES, Antonio Rodrigues.

A psicologia no Brasil. Psicologia: Ciência e

Profissão, v.30, n. especial, p.8-4. 2010. 
VEIGA-NETO. Alfredo.

Teoria e método em Michel Foucault: (im) possibilidades. Cadernos de Educação, v.34, p.8394. set.-dez. 2009.

VENANCIO, Ana Teresa A. Juliano Moreira. In: Campos, Regina Helena de
F. Dicionário biográfico da psicologia no Brasil. Rio de Janeiro: Imago. 2001.

YOUNG, Kimball.

Social psychology. New York: F.S. Crofts. 1945.

\section{$\rightarrow \rightarrow \rightarrow<<<$}

